\title{
Premarital sex in Vietnam: Is the current concern with adolescent reproductive health warranted?
}

\author{
Barbara Mensch \\ Population Council \\ Wesley H. Clark \\ Population Council \\ Dang Nguyen Anh
}

Follow this and additional works at: https://knowledgecommons.popcouncil.org/departments_sbsr-pgy

Part of the Demography, Population, and Ecology Commons, Family, Life Course, and Society Commons, and the International Public Health Commons How does access to this work benefit you? Let us know!

\section{Recommended Citation}

Mensch, Barbara, Wesley H. Clark, and Dang Nguyen Anh. 2002. "Premarital sex in Vietnam: Is the current concern with adolescent reproductive health warranted?" Policy Research Division Working Paper no. 163. New York: Population Council. 
Premarital Sex in Vietnam: Is the

Barbara S. Mensch 


\title{
Premarital Sex in Vietnam: Is the Current Concern with Adolescent Reproductive Health Warranted?
}

\author{
Barbara S. Mensch \\ Wesley H. Clark \\ Dang Nguyen Anh
}

Barbara S. Mensch is Senior Associate and, at the time this study was written, Wesley H. Clark was Staff Research Associate, Policy Research Division, Population Council, New York. Dang Nguyen Anh is Director of the Population and Development Program, Vietnam Asian-Pacific Economic Center, and was Senior Researcher at the Institute of Sociology in Hanoi at the time the survey was conducted.

An earlier version of this paper was presented at the annual meeting of the Population Association of America, Atlanta, 9-11 May 2002. Funding for this research was provided by the Economic Cooperation Bureau, Ministry of Foreign Affairs, Government of Japan; The Rockefeller Foundation; and the United Nations Population Fund.

The authors received helpful comments from Sajeda Amin, Robert Miller, and Sara Peracca. 


\begin{abstract}
To the extent that research on Vietnamese adolescents has been conducted, it has been concerned with unprotected and unsanctioned sexual activity and its health consequences, namely abortion and sexually transmitted diseases, especially HIV. The question we pose is whether this concern is warranted. Is the population community justified in focusing its attention on early sexual activity and HIV risk? Even if the sexual behavior of young people can be considered problematic, are there perhaps other aspects of young people's lives that should give us greater pause? The paper reviews the literature on adolescent sexual behavior in Vietnam and analyzes data on premarital sex and reproductive behavior from a 1999 survey conducted in six provinces among nearly 1,500 adolescent boys and girls aged 15-22. Data on other aspects of young people's lives are summarized, in particular schooling and work, in order to put the sexual activity data in perspective. We conclude that the lack of adequate employment opportunities may be more of a threat to adolescent reproductive health than risky sexual behaviors per se-a situation that effective economic policies can remedy.
\end{abstract}

This material may not be reproduced without written permission from the authors. For a list of Policy Research Division Working Papers, including those available for downloading in PDF format, see www.popcouncil.org/publications/wp/prd/rdwplist.html. 
Beginning in the 1970s, research on adolescents in the United States expanded greatly because of a concern with rising rates of premarital sex and childbearing. Recently, for similar reasons, research on adolescents in Africa, Asia, and Latin America has increased as well. The exporting of the US adolescent problem statement to the developing world has had consequences both for the nature of the data collected on young people and for the topics investigated. This medicalization of the adolescent research agenda has narrowed our lens of vision, limiting the scope of inquiry to sexual and reproductive behavior (Mensch et al. 1998; Bruce and Mensch 1999). Research on adolescents in Vietnam has followed this pattern. To the extent that studies on Vietnamese adolescents have been conducted, they have been concerned primarily with unprotected and unsanctioned sexual activity or the health consequences of that activitynamely abortion and sexually transmitted diseases, especially HIV. This research focus also reflects the view of government officials in Vietnam, whose frequent references to "social evils" in discussions of adolescents suggest that they are troubled about the behavior of the younger generation.

The Vietnam portrayed in the international press is a country where young people have no memory of the American war and are not interested in hearing their elders' tales of hardship and dedication (Schiffrin 1999). Rather, journalists suggest that they are concerned with finding jobs that pay well-possibly at one of the new Vietnameseforeign joint ventures - and in using the money such jobs bring to live an internationalstyle "high life." This sort of life was denied to their parents under prereform Communism, but it is said to attract young people increasingly as foreign products, advertising, movies, and television flood the country. A special issue of TIME magazine ${ }^{2}$ on the shifting social landscape of Asia, for which journalists were instructed to "hit the road, get out into the countryside, and talk to ordinary people" (Morrison 2000:4), devoted an article to "lifestyles of the young and impatient" in Vietnam. Tellingly, and despite the instruction noted above, the focus of the article was on Ho Chi Minh City, the largest city and single most Westernized locale in a country that remains, to this day, 80 percent rural. Discussing sexual behavior, the reporter asserted that "Sex before marriage'eating rice before the bell,' as it was sometimes called-is now the norm" (McCarthy 2000:74). 
The question posed here is whether the current concern about young people in Vietnam is warranted. Is premarital sex really becoming the norm, as media accounts would suggest, or is this finding an artifact of the journalistic tendency to work and gather information in cosmopolitan hubs? Is the population community justified in focusing its attention on early sexual activity and HIV risk? Even if the sexual behavior of young people in Vietnam can be considered problematic, are there perhaps other aspects of young people's lives that should give us greater pause?

Although fertility has declined considerably in Vietnam, relatively high levels of childbearing in the recent past have led to a youthful age structure, as they have in other developing countries. Nearly one-third of Vietnam's population is between 10 and 24 years old (United Nations 2001). These 25 million young people represent the collective demographic and economic future of the country. Yet no study has been conducted in Vietnam that provides a broad picture of young people as they navigate the period between childhood and adulthood. This paper seeks to fill a portion of the knowledge gap about adolescents in Vietnam.

\section{RECENT RESEARCH ON ADOLESCENT SEXUAL AND REPRODUCTIVE BEHAVIOR}

A considerable number of demographic and health studies have been published on Vietnam in recent years. By and large, these have focused on population policy, in particular the one-or-two-child policy; declining fertility and mortality rates, which are lower than expected given the country's income per capita; the high incidence of induced abortion; and the greater reliance on the IUD than on other methods of family planning (Goodkind 1994 and 1995; Knodel et al. 1995; Van Phai et al. 1996; Bryant 1998; Merli 1998).

To the best of our knowledge, no population-based studies on Vietnamese adolescents have been published in peer-reviewed journals. Moreover, studies that explore changes in fertility (see, for example, Haughton 1997) and therefore have the potential to investigate the reproductive knowledge, preferences, and behavior of young people, have been constrained by the fact that the large surveys - the Vietnam Demographic and Health Survey conducted in 1988 and the Vietnam Inter-censal Demographic Survey 
conducted in 1994-are limited to married women. Because of the relatively late age at marriage - fewer than 10 percent of women aged 15-19 in 1992-93 were married (Desai 1998) - those adolescents who are included in the demographic surveys are clearly not representative of that age group as a whole. In contrast to the demographic surveys, the 1993 and 1997-98 Vietnam Living Standards Surveys (VLSS) obtained data on fertility and contraception from all women aged 15-49; but the way in which women were selected for the fertility module, with one woman in the designated age range chosen from each household, is thought to have resulted in a biased sample. (For a discussion of the bias, see Desai 1998.) More important, the VLSS does not include questions about the attitudes and behaviors of adolescents that are of most concern for the present study.

There is a growing body of unpublished research on adolescent reproductive behavior in Vietnam as well as some published studies on clinical or selective samples, such as single women presenting for abortion services in urban hospitals. The major theme running through this research is that social and economic transformations in recent years have altered young people's experiences, expectations, and behavior fundamentally (see, for example, Nhan and Hang 1996; Bélanger and Hong 1998 and 1999; Hong and Mai 1998; and Long et al. 2000). The Confucian ideals of female chastity before marriage, patrilineal family structure and patrilocal residence, ${ }^{3}$ and close and intimate ties between parents and children have begun to change. The introduction of the Doi Moi (renovation) policy in 1986 and the resulting shift toward privatization and away from a planned socialist system has led to a more open economy, rising modernsector employment, increasing availability of cash, and improvements in mass communication, including a greater familiarity with Western culture. As a result, there is said to be a rapid rise in premarital sex and unplanned pregnancies.

This picture of rising rates of premarital sexual activity, escalating numbers of unmarried women terminating unplanned pregnancies, and increasing prevalence of HIV among the young is also suggested by some of the published articles on contraceptive behavior and abortion that are based on larger and more representative data sets. In his 1994 article describing what is known about abortion in Vietnam, Goodkind suggests that the rise in pregnancies among the unmarried is a result of the changing social and economic climate. Contact with the West, asserts Goodkind (1994: 350), "is probably con- 
tributing to a rise in sexual contacts, both premarital and otherwise" and, coupled with the government's unwillingness to provide reproductive health information to young people, has probably led to a rise in premarital pregnancy. Goodkind and Anh (1997) make a similar argument in their paper documenting an increase in condom use in Vietnam. ${ }^{4}$

Although claims about the changing nature of adolescent sexual behavior in Vietnam may seem plausible, particularly in the wake of increasing globalization, little empirical support is found for assertions about rising premarital sex and pregnancy. Instead these claims rely on anecdotal evidence, such as the apparent increase in newspaper articles about the subject (see, for example, Hong 1998) and circumstantial evidence, namely the high abortion rate, which is attributed in part to the large number of young single women who, apparently, are undergoing abortions (Goodkind 1994).

Yet data on the characteristics of women presenting for pregnancy terminations in Vietnam, where the abortion rate is reported to be greater than 100 per 1,000 women aged 15-44, the highest of any country where abortion is legal (Goodkind 1994; Henshaw et al. 1999), indicate that less than 1 or 2 percent are performed on women younger than 20. Goodkind (1994) notes that, according to clinical data, the majority of women obtaining abortions are married, have one or two children, and are between the ages of 25 and 34 (a pattern also found in other developing countries). ${ }^{5}$ Nonetheless, Goodkind suggests, and others concur (Bélanger and Hong 1998 and 1999), that in Vietnam abortion is underreported among adolescents because of the longstanding taboo against premarital sex. He argues that young unmarried women who terminate pregnancies misreport their age and marital status at the time they undergo the procedure.

To document trends in adolescent behavior in Vietnam, researchers have also tried to detect whether attitudes about sexual activity among the unmarried have changed in recent years. There is a consensus in the literature that although the older generation strongly condemns premarital sexual relations, young people are much more inclined to approve of sex before marriage or at least not regard it with "disdain" (Hong 1998:40). Yet, assuming that young people respond candidly to questions about premarital sex (even if they are unwilling to respond accurately about their own sexual behavior), evidence of a widespread sexual revolution taking place in Vietnam is hard to find based on responses to such attitudinal questions. Two recent surveys, one of a sample of approxi- 
mately 1,600 university students aged 17-24 in Hanoi and Ho Chi Minh City and the other of a sample of more than 1,100 young people aged 15-24 in Haiphong City, posed questions about respondents' attitudes concerning premarital sex. The findings of the two surveys were similar: In the Haiphong survey, 93 percent of young women and 70 percent of young men disapproved of sexual activity before marriage; the comparable proportions from the other survey were 98 percent and 74 percent (Nhan and Hang 1996; Anh et al. 1999). Of course, the possibility of courtesy bias, which distorts responses in face-to-face interviews, may be especially pronounced in Vietnam given the Confucian tradition of encouraging respect for those in positions of authority, even though such a tradition may represent more an ideal than current reality. Undoubtedly, youthful respondents perceive interviewers as authority figures. Therefore, survey research on sensitive topics in Vietnam may be particularly problematic.

\section{THE "ADOLESCENTS AND SOCIAL CHANGE IN VIETNAM" SURVEY}

As noted above, Vietnam has experienced profound changes as a result of the introduction of the Doi Moi policy in 1986. Perhaps as a consequence of these economic changes, hints may be found in recent World Bank data of slight declines in school enrollment, especially among girls (Glewwe and Jacoby 1998). An expanding number of studies, cited earlier, point to increases in premarital and unsanctioned sexual activity and also to substance abuse, with all their attendant health, social, and demographic consequences. Most young people today have seen their families' relatively poor economic situation improve over the last decade or so and are aware of the potential for even greater future economic opportunities for themselves. The collapse of the "Asian Miracle" in the 1990s, however, may have led to some confusion and uncertainty about the future (UNDP 1998).

The goal of the Adolescents and Social Change in Vietnam (VASC) survey was to investigate the lives of adolescents in a range of economic, cultural, and environmental conditions at a point in Vietnamese history when aspirations are rising, the health and other risks facing young people are considerable, and the consequences of missing out on available opportunities are potentially severe. 
The VASC survey was undertaken by the Institute of Sociology in Hanoi in collaboration with the Population Council. Interviews were conducted in the fall of 1999 with 2,126 young people aged 13-22. Because resources to conduct a nationally representative study were not available, six of Vietnam's 61 provinces were purposively selected covering a range of urban and rural ecological and cultural zones in the south, north, and center of the country. Their location is shown in Figure 1. In addition to the interviews with adolescents, interviews were conducted with parents, and a community survey was completed in the 24 sample sites.

The six provinces are: Ha Tay in the Red River floodplain adjacent to Hanoi-a rural northern agricultural province that is, nevertheless, within easy range of Hanoi, the largest city in the north; Ho Chi Minh City (Saigon) in the south—Vietnam's largest and most economically active city, site of much of the country's economic expansion and diversification since the commencement of reforms in the mid-1980s; Kien Giang in the far south - a coastal agricultural province; Lai Chau in the far northwest—a rural province in the highlands, inaccessible by land at many times of the year, with a large population of minority ethnic groups; Quang Nam-Da Nang on the central coast-a

Figure 1 Provinces selected for the Adolescents and Social Change in Vietnam Survey, 1999

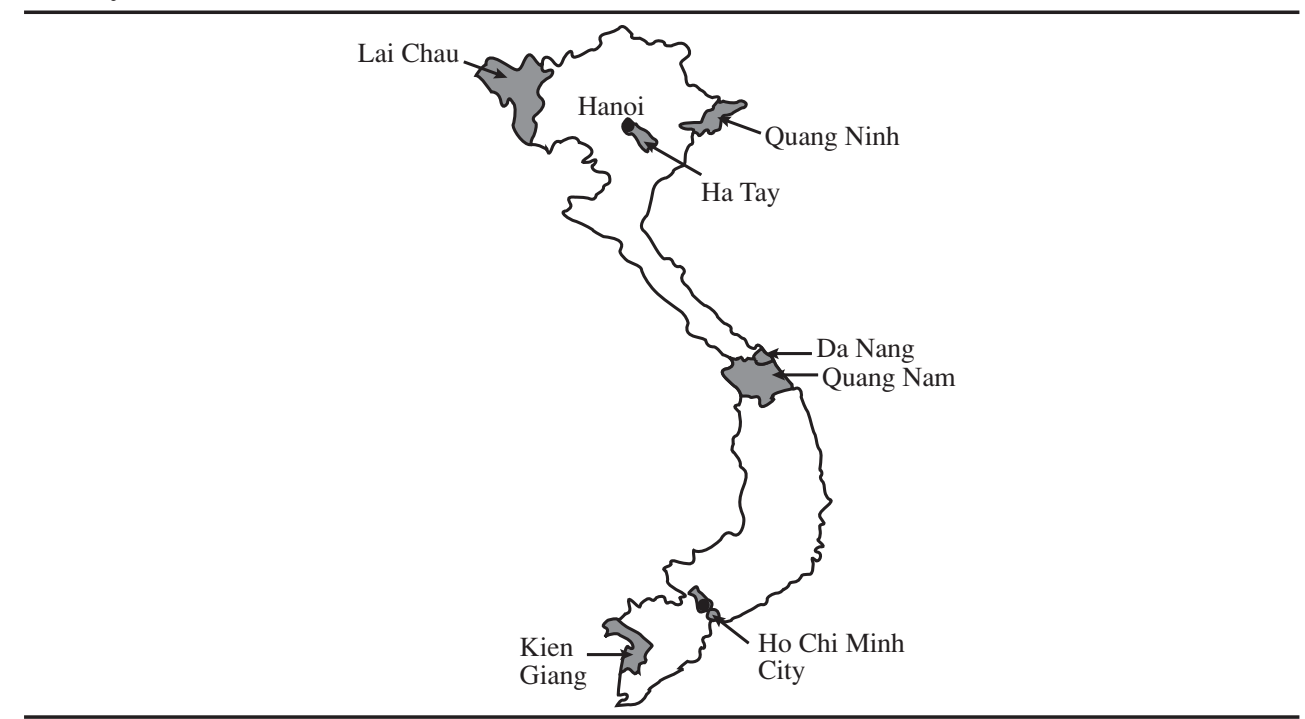


province comprising both urban and rural districts, where local and foreign jointventure light industry has recently been established; and Quang Ninh in the far northeast-a largely rural coastal province at some distance from Hanoi, where coal mining is a major activity.

In each province, two (or, in the case of Ho Chi Minh City, three) ${ }^{6}$ districts were randomly selected for fieldwork. In each district, two wards (urban) or communes (rural), the country's smallest administrative units, were then randomly selected. ${ }^{7}$ The distribution of wards/communes in each province was based on the urban-rural distribution of the province's population, with the result that 19 communes and five wards were designated for inclusion. The distribution of communes and wards in the sample reflects the urban-rural breakdown in Vietnam as a whole: Currently 80 percent of Vietnam's population lives in rural areas. Once the distribution of communes and wards was determined, selection of a particular ward or commune was random. Household listings for each ward and commune were obtained from local authorities. Because the 1999 Population and Housing Census had been completed recently, listings were likely to be reasonably complete. One hundred households including an adolescent aged 13-22 were randomly selected for the survey in each ward or commune. In households with multiple adolescents, one was randomly selected for the interview. Out of the 2,400 adolescents selected, 2,126 or 89 percent were interviewed. Although this response rate is high for a young adult survey, those who were not interviewed differed from those who were-in particular, they tended to be older and disproportionately male. Table 1 indicates the age distribution of the adolescent sample by sex.

The survey included three instruments: a roster administered to an adult residing in each household (preferably a parent), an adolescent questionnaire, and a community

Table 1 Percentage distribution of the VASC sample, by age and sex, Vietnam, 1999

\begin{tabular}{lcc}
\hline Age & Males & Females \\
\hline $13-14$ & 22 & 21 \\
$15-16$ & 28 & 25 \\
$17-18$ & 21 & 22 \\
$19-20$ & 18 & 19 \\
$21-22$ & 11 & 12 \\
$(\mathrm{~N})$ & $(985)$ & $(1,141)$ \\
\hline
\end{tabular}


questionnaire administered to a local authority in each ward or commune. The analysis here relies primarily on the adolescent questionnaire, which included basic demographic questions as well as questions about family background; educational history; daily time use; work history; experiences with regard to puberty, menstruation, marriage, sex, pregnancy, abortion, and birth; reproductive health and family planning knowledge and experience; drug and alcohol use; recreational activities; and mobility and migration. Information was also obtained from the household roster/questionnaire that collected data on the name, age, sex, education, health, and work status of all usual household residents as well as anyone aged 13-22 who used to live in the household but currently resides elsewhere. The instrument also included questions about household assets, amenities, main sources of income, and the ethnicity and religion of the family.

\section{RESULTS}

The sample is drawn from widely varying regions of Vietnam, deliberately chosen because they represent the range of environments experienced by Vietnamese young people today. Because the sample is not nationally representative, it is misleading to combine the data across provinces and present the results as if they characterize Vietnamese adolescents as a whole. In analyses for which the sample is too small to disaggregate the data by province, the results can only be generalized to the six provinces included in the survey and not to Vietnam as a whole.

\section{Premarital sex}

In the VASC survey, respondents aged 15 and older were asked whether they had ever had sexual relations and, if so, at what age they first did so. The analysis in this paper is restricted, therefore, to the responses of the 1,497 adolescents aged 15-22. For those who had married, the information on age at first intercourse was then compared with the responses on marriage to determine whether sex had occurred prior to marriage. Among the 764 males aged 15-22 for whom information on sexual behavior was available, only 10 percent report having had premarital sex; among the 733 females in the same age category, only 5 percent report having had premarital sex. As Table 2 
shows, the reported premarital sex rates for males vary considerably by province, from none in Quang Nam-Da Nang to 19 percent in Ho Chi Minh City. For females, the proportion reporting premarital sex ranges between 2 and 9 percent.

Table 3 compares the proportion of never-married Vietnamese 15-19-year-olds who have ever had sex with data from two other Southeast Asian countries, the Philippines and Thailand, that have data for both boys and girls. ${ }^{8}$ Boys appear to be less likely to engage in sex prior to marriage in Vietnam compared with boys in the other two countries. Although the aggregate data for Vietnam may be misleading in that the sample is not nationally representative, the level of premarital sex observed in five of six provinces is so low that, were a national survey to be conducted, reported rates clearly would be lower among boys in Vietnam than elsewhere. Only in Ho Chi Minh City, where 11 percent of unmarried boys aged 15-19 report having had sex, does the rate approach those of the other countries; but, as noted above, Ho Chi Minh City is not representative of Vietnam. In contrast with the rates for boys, the reported rates for adolescent girls are low in the other two Southeast Asian countries as well. When the comparison is broadened to include countries in Latin America and sub-Saharan Africa, Vietnam and, by extension, the other two countries in Table 3, stand out. In all 32 African and Latin American countries where a Demographic and Health Survey has been conducted, rates of premarital sex among adolescent girls are higher than those found in Vietnam, and in 31 of the 32, the proportion of girls who report having had premarital sex is at least twice as high as in Vietnam. ${ }^{9}$

Table 2 Percentage of 15-22-year-olds who reported having had premarital sex, by province, Vietnam, 1999

\begin{tabular}{lcc}
\hline Province & Males & Females \\
\hline Ha Tay & 3 & 2 \\
Ho Chi Minh City & 19 & 3 \\
Kien Giang & 15 & 9 \\
Lai Chau & 13 & 8 \\
Quang Nam-Da Nang & 0 & 3 \\
Quang Ninh & 13 & 9 \\
Total & 10 & 5 \\
(N) & $(764)$ & $(733)$ \\
\hline
\end{tabular}


Table 3 Percentage of never-married 15-19-year-olds who have ever had sex, by country

\begin{tabular}{lcc}
\hline Country & Males & Females \\
\hline Vietnam & 6 & 2 \\
& (provincial range 0-11) & (provincial range 0-3) \\
Philippines & 12 & 1 \\
Thailand & 27 & 3 \\
\hline
\end{tabular}

Source: For Philippines and Thailand, see Singh et al. 2000.

Given that sexual activity is often initiated between the ages of 15 and 22, a life table is a more appropriate tool for analyzing premarital sex in an adolescent sample. Figure 2, which indicates the probability of initiating premarital sex separately by sex for the sample as a whole, is based on an analysis of both current status and retrospective questions. Clearly, little premarital sex occurs before the age of 18; just over 6 percent of boys and under 4 percent of girls are predicted to initiate sex by their eighteenth birthday. Again, this finding contrasts sharply with the experience of adolescents in sub-Saharan Africa and Latin America (AGI 1998). By their twenty-second birthday,

Figure 2 Probability of adolescent males and females aged 15-22 having premarital sex, Vietnam, 1999

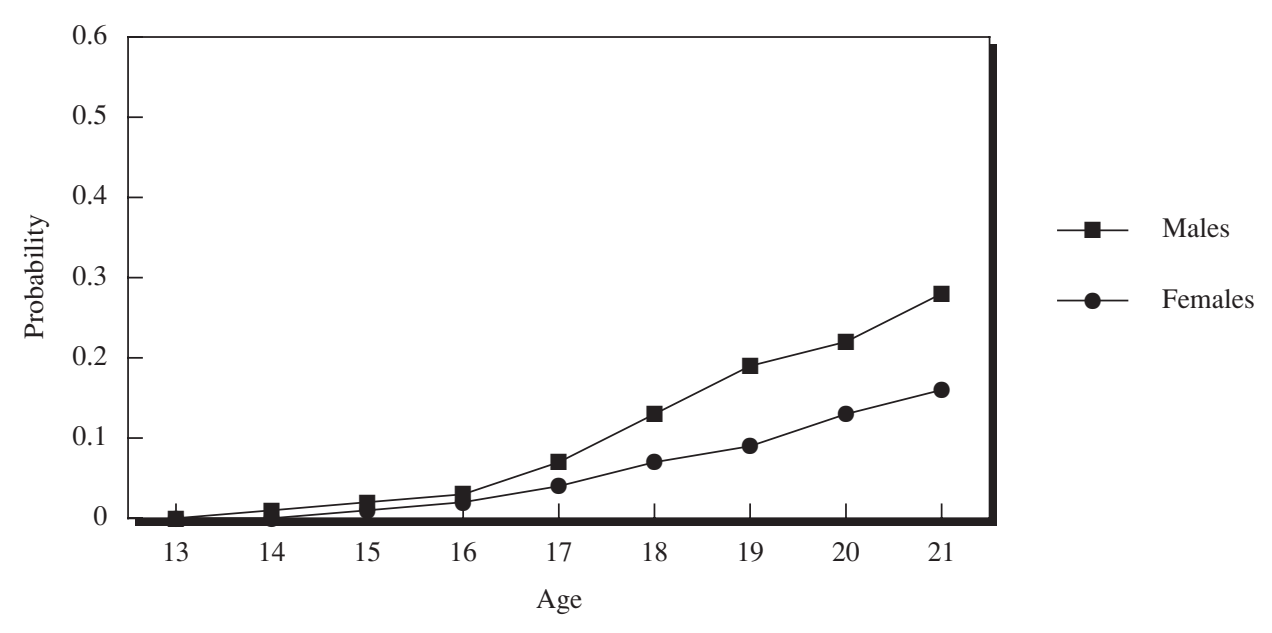


approximately 29 percent of unmarried young men and 16 percent of unmarried young women in Vietnam are predicted to have had sexual intercourse.

In comparing the estimates of premarital sex among never-married women with those among the married and unmarried combined, reporting of premarital sex among the married clearly is higher. Figure 3 shows the probability of initiating premarital sex by marital status for women. (Males are excluded because too few young men in the sample are married for this analysis to be conducted for them.) About half of married women in the sample-approximately 18 percent of those aged 15-22 are marriedreport having had premarital sex by their twenty-first birthday. This finding contrasts with 6 percent among the unmarried. The question remains whether the higher level of premarital sex observed reflects a greater willingness among the married to disclose information about sensitive behavior in a face-to-face interview; that is, once married, do women feel freer to talk about premarital sex? Moreover, evidence from the National Longitudinal Survey in the United States suggests that adolescents are more likely to "conceal" sexual activity initiated in the period close to the interview (Wu et al. 2001). An alternative hypothesis explaining the differences in reporting is that, having decided

Figure 3 Probability of adolescent females aged 15-22 having premarital sex, by current marital status, Vietnam, 1999

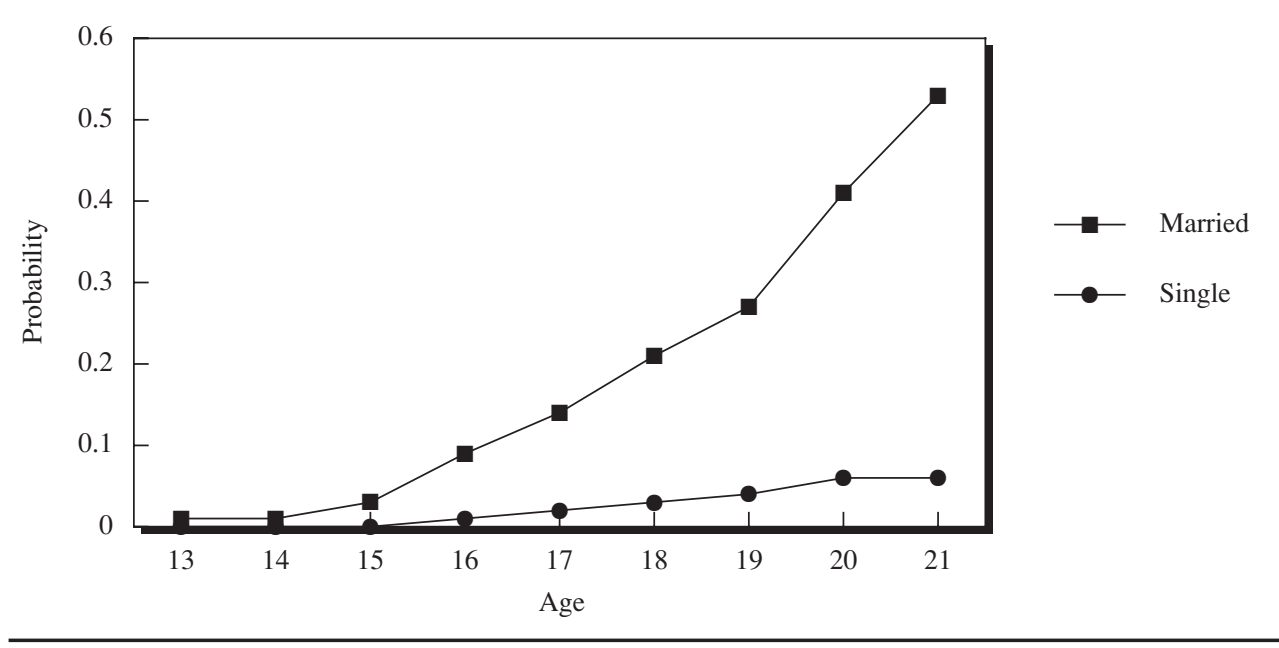


to marry, women may feel comfortable about having sex with their fiancés because societal proscriptions against premarital sex are likely loosened when sexual activity occurs with the future spouse. Determining which scenario characterizes the situation in Vietnam is important because if the higher rate of premarital sex reported among married women is attributable to a greater inclination of these women to talk openly about their behavior, premarital sex among young people is likely to be much more common than these data demonstrate.

To address the issue of the increased level of premarital sex observed among the married, responses to the question about the first sexual partner were analyzed. Among married women who reported that they had had premarital sex, 87 percent initiated sex with the man who later became their husband. So although the married are more likely to have engaged in premarital sex, it is premarital sex with a future husband and, therefore, unlikely to be considered a "social evil" in the eyes of most Vietnamese.

A comparison of HIV prevalence across countries suggests that the data collected concerning premarital sex are not totally off the mark. According to UNAIDS, Vietnam has much lower rates of HIV prevalence among 15-24-year-olds than does Cambodia, Myanmar, or Thailand. Interestingly, in contrast with these countries, the prevalence of $\mathrm{HIV}$ in Vietnam is higher among males than females in this age group (see Table 4). ${ }^{10}$ When rates are higher among young men than young women, transmission is likely occurring through sharing needles among drug users; drug users, in turn, infect others through sexual activity. Indeed, according to UNAIDS and WHO (2000), in 1998-99 the majority (64 percent) of new HIV infections in Vietnam were estimated to occur among injecting drug users.

Table 4 UNAIDS high estimates of the percentage of young people aged 15-24 infected with HIV

\begin{tabular}{lcc}
\hline Country & Males & Females \\
\hline Cambodia & 3.77 & 4.70 \\
Laos & 0.05 & 0.05 \\
Myanmar & 1.67 & 2.30 \\
Thailand & 1.89 & 3.11 \\
Vietnam & 0.38 & 0.10 \\
\hline
\end{tabular}

Source: UNAIDS and WHO 2000. 


\section{Sexual activity among peers}

Before we can conclude that premarital sex among adolescents in Vietnam is much less common than is widely thought, we must be confident that adolescents are not underreporting sexual activity, particularly in comparison with their peers in other countries. Indeed, the finding that not one boy in Quang Nam-Da Nang reported having had premarital sex suggests that underreporting is a potential problem.

Although additional data collection is needed to assess the degree of underreporting of premarital sex among young people, we sought to determine this with our own data. In addition to being questioned about their own sexual behavior, respondents were asked whether their best friend had ever had sex, because young people are likely to be more honest in providing information about their friends' behavior than about their own. Of those whose best friend was not married, 14 percent of boys $(n=646)$ and 9 percent of girls $(n=717)$ indicated that their friend had had sex. These proportions are indeed higher than those that respondents reported for their own behavior. Assuming that their friends' behaviors mirror their own, this finding constitutes indirect evidence that some underreporting of sexual activity exists among boys and girls. No data are available concerning the sexual behavior of respondents' friends in other countries; we assume that, as in Vietnam, rates for other countries reported for friends would be higher than rates reported by respondents for themselves. Unless the underreporting is much greater in Vietnam than in other countries, however, the data suggest that premarital sex among adolescent boys is lower in Vietnam compared with other developing countries in Southeast Asia, Latin America, and sub-Saharan Africa.

\section{Dating behavior}

Because underreporting of premarital sexual activity was anticipated, we also asked respondents about their dating behavior because, more often than not, dating precedes sexual activity. Not only do responses about dating give a sense of the numbers at risk of having premarital sex, they also indicate how young people in Vietnam interact with one another. Specifically, males were asked whether they had ever had a girlfriend, and females were asked whether they had ever had a boyfriend. Table 5, in which findings are limited to unmarried respondents aged 15-22, indicates that dating, defined as 
Table 5 Percentage of unmarried respondents aged 15-22 reporting that they ever had a girlfriend or boyfriend, by province and sex, Vietnam, 1999

\begin{tabular}{lcc}
\hline Province & Males & Females \\
\hline Ha Tay & 19 & 26 \\
Ho Chi Minh City & 36 & 32 \\
Kien Giang & 26 & 23 \\
Lai Chau & 13 & 29 \\
Quang Nam-Da Nang & 7 & 11 \\
Quang Ninh & 18 & 19 \\
Total & 20 & 23 \\
(N) & $(730)$ & $(733)$ \\
\hline
\end{tabular}

having a girlfriend or boyfriend, is much more common than having premarital sex, particularly among females, who in some provinces report higher rates for dating than do males. As expected, the likelihood of having a girlfriend or boyfriend increases markedly with age (not shown). Among young men, 14 percent of those aged 15-19 and 39 percent of those aged 20-22 report having had a girlfriend; the analogous numbers for young women are 19 percent and 40 percent—proportions that by Western standards are not particularly high.

We also sought to determine whether respondents socialized with members of the opposite sex by asking them to report on how they spent their time the day before the interview. We divided the day into seven segments, from midnight to 5 A.M., 6 A.M. -9 A.M., 10 A.M.-noon, 1 P.M.-3 P.M., 4 P.M.-6 P.M., 7 P.M. -9 P.M., and 10 P.M.-midnight. For each segment, respondents were asked to list the activities that occupied their time, beginning with the activity that took up the most time during that period. If respondents were currently attending school, they were asked to list their activities during the last school day. ${ }^{11}$ There were 14 activity categories, including sleeping, personal care, transit to and from school or work, at school or work, domestic duties, helping on a family farm or business, and recreation. Recreation was further divided into whether it took place at home or elsewhere, and whether it involved the respondent alone or took place with family or with friends of the same or opposite sex. The proportion who specified that they spent some time the day before the interview socializing with a member of the opposite sex is shown in Table 6, in which the data are again limited to responses from unmar- 
Table 6 Percentage of unmarried respondents aged 15-22 who engaged in any recreational or social activity with someone of the opposite sex, by province and sex, Vietnam, 1999

\begin{tabular}{lcc}
\hline Province & Males & Females \\
\hline Ha Tay & 3 & 3 \\
Ho Chi Minh City & 4 & 2 \\
Kien Giang & 14 & 7 \\
Lai Chau & 4 & 10 \\
Quang Nam-Da Nang & 11 & 3 \\
Quang Ninh & 24 & 21 \\
Total & 9 & 7 \\
(N) & $(731)$ & $(733)$ \\
\hline
\end{tabular}

ried adolescents aged 15-22. ${ }^{12}$ Overall, only 9 percent of males and 7 percent of females spent time with someone of the opposite sex. Moreover, of those currently attending school, only 2 percent of both boys and girls spent some time with a member of the opposite sex (not shown). (The comparable numbers for those not in school were 16 percent for males and 11 percent for females.) Interestingly, although time spent with someone of the opposite sex increases with age for males (6 percent for those aged 15-19 and 20 percent for those 20-22), it does not for females (7 percent both for those aged 15-19 and for those aged 20-22), a finding that may reflect girls' increasing domestic responsibilities as they age (not shown) (Population Council and Institute of Sociology 2000).

\section{Pregnancy, abortion, and childbearing}

In light of the low levels of premarital sex that respondents reported in the VASC survey, it follows that reported rates of premarital pregnancy and childbearing will also be low. Indeed, of the 733 unmarried women aged 15-22 in the sample, only four reported a pregnancy; two of the four reported an abortion or menstrual regulation, and only one reported a birth.

On the other hand, childbearing is not uncommon among the married women in the sample. Of the 164 women who are married, 122 (74 percent) have had a child and 18 (11 percent) reported having had an abortion or using menstrual regulation. Because early marriage is not common in Vietnam, however, overall rates of teenage childbear- 
ing are low. To monitor early childbearing, demographers often compute the proportion of women who have a child by age 18 or 20 among those older than 20 in different age cohorts. Unfortunately, because the VASC survey includes women only to age 22, the denominator for this calculation is small, limited to women aged 20-22. Nonetheless, because a comparable measure of adolescent childbearing is available for many countries, it is worthwhile to include it here.

As Table 7 shows, 20 percent of women aged 20-22 gave birth before they were 20 , virtually all, as indicated above, within marriage. Among 46 other developing countries for which published data are readily available, only four have proportions lower than this for women aged 20-24 (AGI 1998). The United States, which is unusual among wealthy countries in the large proportion of women who give birth as teenagers, has a rate of 22 percent, with 62 percent of these births being to unmarried women. With regard to earlier childbearing-before the age of 18-Vietnam is even more unusual. Only China, among developing countries, has a lower proportion; the rate for the US is 9 percent. As noted above, however, because the sample is not nationally representative, the aggregate data may be misleading. Although the provincial samples are small, we have presented them to demonstrate the enormous variability in the country. Lai Chau, which clearly represents one extreme, has a much higher rate of childbearing before age 20 than do the other provinces; it is comparable, however, to that of most Latin American countries and lower than the rate in virtually all sub-Saharan African countries. Although the rate of childbearing before age 20 is higher in Lai Chau than in many other

Table 7 Percentage of women aged 20-22 who gave birth before age 18 and before age 20, by province, Vietnam, 1999

\begin{tabular}{lcc}
\hline Province & Gave birth before age 18 & Gave birth before age 20 \\
\hline Ha Tay & 0 & 19 \\
Ho Chi Minh City & 3 & 11 \\
Kien Giang & 6 & 21 \\
Lai Chau & 9 & 44 \\
Quang Nam-Da Nang & 0 & 5 \\
Quang Ninh & 5 & 22 \\
Total & 4 & 20 \\
(N) & $(242)$ & $(242)$ \\
\hline
\end{tabular}


Asian countries, the rate for those younger than 18 is comparable to the rates for that age group observed in most other Asian countries.

From the data presented here, adolescent reproductive behavior does not appear to be particularly problematic in Vietnam, at least not at this time. The vast majority of adolescents indicate that they are not engaging in premarital sex. In fact most young women who are having sex prior to marriage report doing so with their future spouse. Nor are young people spending a lot of time socializing with members of the opposite sex or dating, as are their counterparts in the West. HIV infection, a health problem that obviously must be monitored, remains at low levels among 15-24-year-olds, particularly among young women. Moreover, although knowledge does not necessarily translate into use, according to the VASC survey the majority of young people in Vietnam appear to be familiar with condoms. In the interview, we assessed both spontaneous and probed $^{13}$ knowledge of contraceptive methods. Among 15-22-year-olds, spontaneous knowledge of condoms is 69 percent (ranging from 43 percent in Lai Chau to 88 percent in Ho Chi Minh City) and probed plus spontaneous knowledge is 86 percent (ranging from 61 percent in Lai Chau to 96 percent in Ha Tay). A comparison of condom awareness as reported in the VASC survey with data from other countries reveals that Vietnamese adolescents are as knowledgeable as their peers in Asia and Latin America and more knowledgeable than their peers in sub-Saharan Africa (Population Council and Institute of Sociology 2000). Finally, premarital childbearing is rare, and the rate of teenage childbearing within marriage is low by comparison with that of other developing countries.

If rates of premarital sex, childbearing, and HIV infection are not currently high among young Vietnamese, why is the government so concerned? Perhaps policymakers living in Hanoi have seen the night clubs and karaoke bars that have opened in recent years in cities, especially in Ho Chi Minh City, and have become anxious about young people's exposure to the global youth culture. The international press has drawn attention to these new clubs and bars and their patrons, conferring on them an even higher profile. The question is whether the presence of these establishments, which were much less common in pre-Doi Moi Vietnam, signals a transformation in the behavior of young people throughout the country or represents merely a lifestyle change for the urban elite. 


\section{Problems Facing Vietnamese Youth}

If the sexual and reproductive behavior of adolescents is not a major cause for concern, what are the critical problems facing young people as they make the transition to adulthood in Vietnam? In the VASC survey, we asked respondents to identify their biggest concern or worry for themselves in the five years ahead. This analysis is not presented according to province because the tables become unwieldy. Moreover, considerably more variability is found by age than by residence. Although education is a worry for younger adolescents, the issue that troubles young people the most is employment and/or poverty (see Table 8a). Even young women are more concerned about their economic circumstances than they are about traditional female domains such as family, marriage, and childbearing. As for young people's worries about society at large, the category of "social evils" heads the list of major concerns, which is not surprising in light of the publicity the government has given to this issue. Unemployment is a close second, however (see Table $8 \mathrm{~b}) .{ }^{14}$

Table 8a Percentage of 15-22-year-old males and females who cite specific concerns for the upcoming five years, by age and sex, Vietnam, 1999

\begin{tabular}{|c|c|c|c|c|c|c|c|c|}
\hline \multirow[b]{2}{*}{ Age } & \multicolumn{2}{|c|}{ Employment/poverty } & \multicolumn{2}{|c|}{ Education } & \multicolumn{2}{|c|}{ Health } & \multicolumn{2}{|c|}{$\begin{array}{c}\text { Family/marriage/ } \\
\text { childbearing }\end{array}$} \\
\hline & Males & Females & Males & $\overline{\text { Females }}$ & Males & $\overline{\text { Females }}$ & Males & $\overline{\text { Females }}$ \\
\hline$\overline{15-17}$ & 58 & 59 & 53 & 43 & 23 & 25 & 15 & 24 \\
\hline $18-19$ & 80 & 70 & 30 & 21 & 19 & 20 & 26 & 39 \\
\hline $20-22$ & 81 & 75 & 14 & 11 & 26 & 32 & 34 & 39 \\
\hline Total & 69 & 66 & 38 & 29 & 23 & 25 & 23 & 32 \\
\hline
\end{tabular}

Note: Multiple responses are possible.

Table 8b Percentage of 15-22-year-old males and females who cite specific concerns about present-day society, Vietnam, 1999

\begin{tabular}{lcc}
\hline Concern & Males & Females \\
\hline "Social evils" & 76 & 75 \\
Unemployment & 64 & 66 \\
Environment & 59 & 59 \\
Family & 35 & 38 \\
Economic stratification & 30 & 32 \\
Corruption & 29 & 26 \\
\hline
\end{tabular}

Note: Multiple responses are possible. 


\section{Substance use}

In enumerating problems facing young people in Vietnam, the first considered here is substance use, which falls into the government's category of "social evils." In the VASC survey, respondents were asked about heroin and cocaine use; only 1 percent of boys and less than 1 percent of girls report that they have ever experimented with these drugs. Even though few adolescents in the sample admit to using these substances, a problem with narcotics may, nevertheless, exist in the six provinces sampled. Most likely respondents were unwilling to discuss drug use with the interviewers. Indeed, when respondents were asked whether they had a friend who used heroin or cocaine, 10 percent of boys and 9 percent of girls said that they did, responses that give indirect evidence both of serious underreporting in this sample and of a potential problem with substance use among young people in Vietnam. For a population-based survey, these numbers are high, supporting the popular perception that illegal substances are widely available and abused, at least among certain segments of the population (McCarthy 2000).

\section{Schooling}

Because a large fraction of the younger respondents are concerned or worried about their education, we investigate rates and reasons for leaving school among those aged 15-22 in the VASC sample. In general, educational attainment, as measured by enrollment in primary school, is high in Vietnam, especially in light of the poverty suffered by much of the population. According to the VASC data, Lai Chau is the only study province where fewer than 95 percent of adolescents have ever been to school: For girls, the rate in Lai Chau is 75 percent; for boys, 93 percent. An analysis of trends in schooling in Vietnam from 1980 through the early 1990s indicated that enrollment declined in the 1980s, probably because of the increased opportunity cost of schooling that accompanied the transition to a market economy and the decollectivization of communes (Glewwe and Jacoby 1998). The VASC data indicate that some improvement in school enrollment occurred during the latter part of the 1990s; at that time, younger adolescents (aged 13-17) were predicted to progress farther in school than older ones (aged 18-22), a change observed in the 1997-98 VLSS as well (Glewwe and Jacoby 2002). 
Although the vast majority of adolescents have been to school, levels of attainment vary considerably among different population groups. Indeed, according to Figure 4 (which is based on life-table estimates), young people in rural areas are much more likely to leave school early than are their urban peers. The hazard rate of leaving school after completing grade 5 (the end of primary school) is more than four times higher among girls living in rural areas than among those in urban areas. Likewise, the hazard rate of leaving school after completing grade 9 (the end of lower secondary school) is nearly seven times higher among boys living in rural areas than among their counterparts in urban areas. That the urban-rural gap is much greater than the gap between boys and girls is consistent with Knodel and Jones's (1996) observation that socioeconomic differentials in educational attainment are much larger in Vietnam than gender differentials, and with Glewwe and Jacoby's (1998) finding regarding the rising opportunity cost of schooling in rural areas. When respondents in the VASC survey who were no longer enrolled in school were asked the reasons why they had left, the most common reason given by boys and girls in both rural and urban areas was that their families could not afford the cost of school (see Table 9). Vietnam introduced school fees in 1989, and although tuition is not the major cost of schooling (Glewwe and Jacoby 1998), access to

Figure 4 Probability of adolescents' being enrolled in school, by sex and residence, according to grade level, Vietnam, 1999

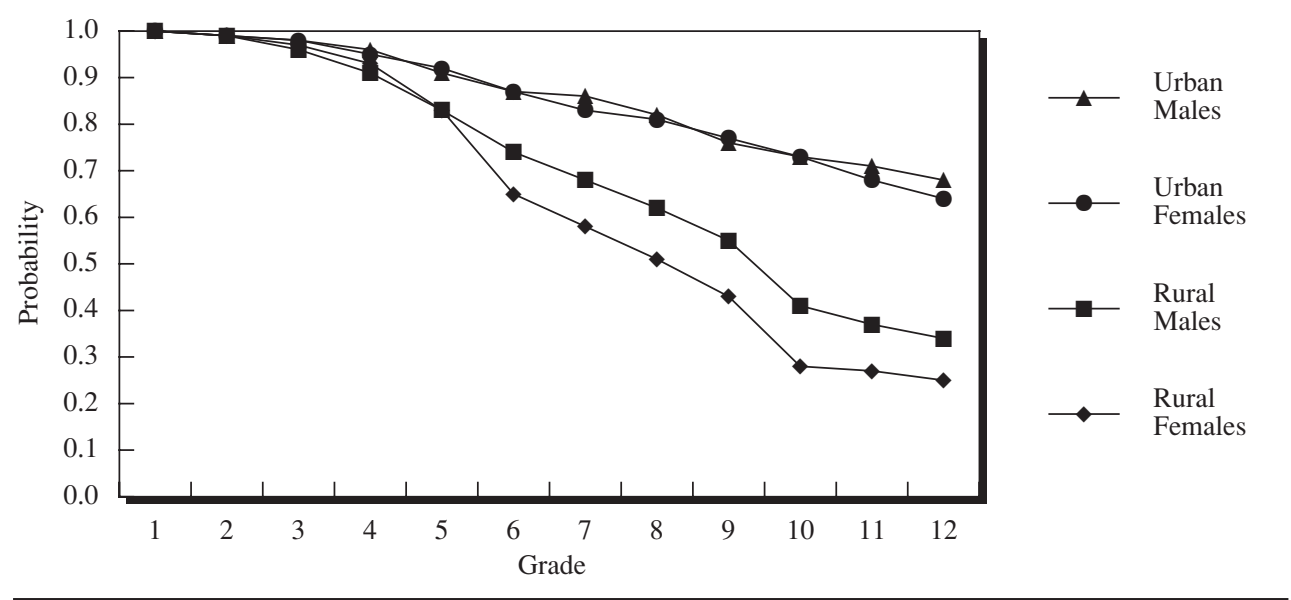


Table 9 Percentage of males and females aged 15-22 who left school, by main reason for leaving, according to residence, Vietnam, 1999

\begin{tabular}{lrrrrrr}
\hline & \multicolumn{2}{c}{ Males } & & \multicolumn{2}{c}{ Females } \\
\cline { 2 - 3 } \cline { 5 - 6 } Reason & Urban & Rural & & Urban & Rural \\
\hline Family could no longer pay school fees & 31 & 35 & & 39 & 34 \\
Work at home/child-care responsibilities/job & 19 & 19 & & 9 & 18 \\
Poor performance at school & 22 & 13 & & 7 & 10 \\
Access to/quality of school & 19 & 10 & & 30 & 8 \\
Completed level & 7 & 13 & & 11 & 16 \\
Miscellaneous & $(58)$ & $(345)$ & & $(94)$ & $(489)$ \\
(N) & & & &
\end{tabular}

education and higher-quality schooling varies by income because of other schoolrelated expenditures (Behrman and Knowles 1999). Indeed, using data on consumption expenditures to measure wealth, a recent analysis of the growth in school enrollment in Vietnam between 1993 and 1998 finds a substantial effect of household financial status on the demand for education (Glewwe and Jacoby 2002). That both the quantity and quality of schooling is dependent on income is clearly a concern for a Vietnamese government dedicated, at least nominally, to social and economic equity.

\section{Current work status and underemployment}

Employment and poverty are the primary concerns for the future mentioned by the survey respondents. The data demonstrate that strong justification exists for their anxiety. Table 10 provides information on employment status in the week before the interview among all boys who are not in school and among unmarried girls ${ }^{15}$ who are not in school. ${ }^{16}$ The definition of work used here includes work for payment in cash or in kind and work in a family business or farm. ${ }^{17}$ Although rates of nonwork-which we define more broadly than most conventional measures of unemployment in that "discouraged" workers are included here-vary considerably, they are high for boys in all provinces and for girls everywhere but in Ha Tay. The provincial rates mask the point that it is really urban residence that makes the difference rather than residence in a particular region. As the total column in Table 11 reveals, rates of nonwork for both boys and girls are twice as high in urban as in rural areas, although even in rural areas approxi- 
Table 10 Percentage of out-of-school respondents aged 15-22 who are not working, by province, Vietnam, 1999

\begin{tabular}{lcc}
\hline Province & Males & Unmarried females \\
\hline Ha Tay & 16 & 4 \\
Ho Chi Minh City & 40 & 36 \\
Kien Giang & 24 & 22 \\
Lai Chau & 21 & 18 \\
Quang Nam-Da Nang & 39 & 43 \\
Quang Ninh & 19 & 22 \\
Total & 24 & 23 \\
(N) & $(459)$ & $(530)$ \\
\hline
\end{tabular}

mately one-fifth of out-of-school adolescents are not working. It is noteworthy that those who are most likely to be currently unemployed are the better-educated urban dwellers. More than half of the respondents of both sexes living in urban areas and having at least some secondary education were not working in the week prior to the survey.

The data indicate that a substantial fraction-39 percent of males and 45 percent of unmarried females - of those who are out of school but not working are not currently looking for paid employment (not shown). Indeed, a substantial proportion of young people do not appear to be engaged in any organized activity. Table 12 shows the proportions of respondents who are neither currently working nor in school according to residence and age. In both rural and urban areas, these rates increase with age so that by ages 20-22, about one-fifth of boys and nearly one-fourth of unmarried girls are neither working nor in school. Interestingly, of those categorized as "doing nothing," nearly three-fourths of males and nearly two-thirds of females have worked in the past 12

Table 11 Percentage of out-of-school respondents aged 15-22 who are not working, by residence, according to educational attainment, Vietnam, 1999

\begin{tabular}{|c|c|c|c|c|c|c|c|c|}
\hline \multirow[b]{2}{*}{ Residence } & \multicolumn{4}{|c|}{ Males } & \multicolumn{4}{|c|}{ Unmarried females } \\
\hline & $\begin{array}{c}\text { Some } \\
\text { primary }\end{array}$ & $\begin{array}{c}\text { Completed } \\
\text { primary }\end{array}$ & $\begin{array}{c}\text { Some } \\
\text { secondary }\end{array}$ & Total & $\begin{array}{c}\text { Some } \\
\text { primary }\end{array}$ & $\begin{array}{c}\text { Completed } \\
\text { primary }\end{array}$ & $\begin{array}{c}\text { Some } \\
\text { secondary }\end{array}$ & Total \\
\hline Urban & - $^{\mathrm{a}}$ & 46 & 54 & 47 & $-\mathrm{a}^{\mathrm{a}}$ & 24 & 52 & 42 \\
\hline Rural & 19 & 18 & 24 & 20 & 9 & 21 & 22 & 19 \\
\hline Total & 20 & 22 & 29 & 24 & 13 & 21 & 30 & 23 \\
\hline
\end{tabular}

a Fewer than 20 respondents in this category. 
Table 12 Percentage of all males and unmarried females aged 15-22 who reported "doing nothing," by residence and age, Vietnam, 1999

\begin{tabular}{|c|c|c|c|c|c|c|c|c|}
\hline \multirow[b]{3}{*}{ Residence } & \multicolumn{6}{|c|}{ Age } & & \\
\hline & \multicolumn{2}{|c|}{ 15-17 } & \multicolumn{2}{|c|}{ 18-19 } & \multicolumn{2}{|c|}{$20-22$} & \multicolumn{2}{|c|}{ Total } \\
\hline & Males & Females & Males & $\overline{\text { Females }}$ & Males & Females & Males & Females \\
\hline Urban & 15 & 14 & 20 & 15 & 19 & 33 & 18 & 19 \\
\hline Rural & 7 & 10 & 17 & 18 & 19 & 18 & 12 & 13 \\
\hline Total & 8 & 11 & 17 & 17 & 19 & 23 & 13 & 15 \\
\hline
\end{tabular}

a Doing nothing: not in school, no work (either paid or unpaid) in the last week.

months (not shown). This finding suggests that both unemployment and stability of employment are problems facing young people in Vietnam. ${ }^{18}$

The VASC data demonstrate that a large reservoir of young people in Vietnam are neither in school nor working on a steady basis. Given rapid economic growth, a reduction in poverty, greater integration into the world economy, and access to Western media, surely many if not most of them, particularly the better-educated urban dwellers, have aspirations for a higher standard of living than that of their parents. The absence of sufficient work opportunities for this large cohort of out-of-school adolescents could prove problematic both for them and for society at large. The frustrations of young people who have been well educated but lack opportunities for economic advancement could begin to express themselves in self-destructive behaviors including drug use and casual sexual encounters. Were this the case, it would not be "social evils" per se that are threatening the futures of young people, but rather the economic conditions that give rise to such evils. In such a scenario, the Vietnamese government's focus on combating the evils themselves would seem to be a case of treating the symptoms rather than the disease. ${ }^{19}$

On the other hand, if Vietnam follows in the footsteps of the East Asian Tigers by capitalizing on the increase in the adult population of working age relative to the dependent population, economic growth may be greatly enhanced (Dollar and Litvack 1998; Williamson 2001). This so-called demographic gift, which is a consequence of fertility decline, is one reason economists now believe that other East Asian countries had such high levels of economic growth in the past 30 years (Birdsall and Sinding 2001; Bloom and Canning 2001). In Vietnam, as Figure 5 indicates, the ratio of the working-age popu- 
Figure 5 Ratio of working-age population to dependent population, 1950-2025, Vietnam

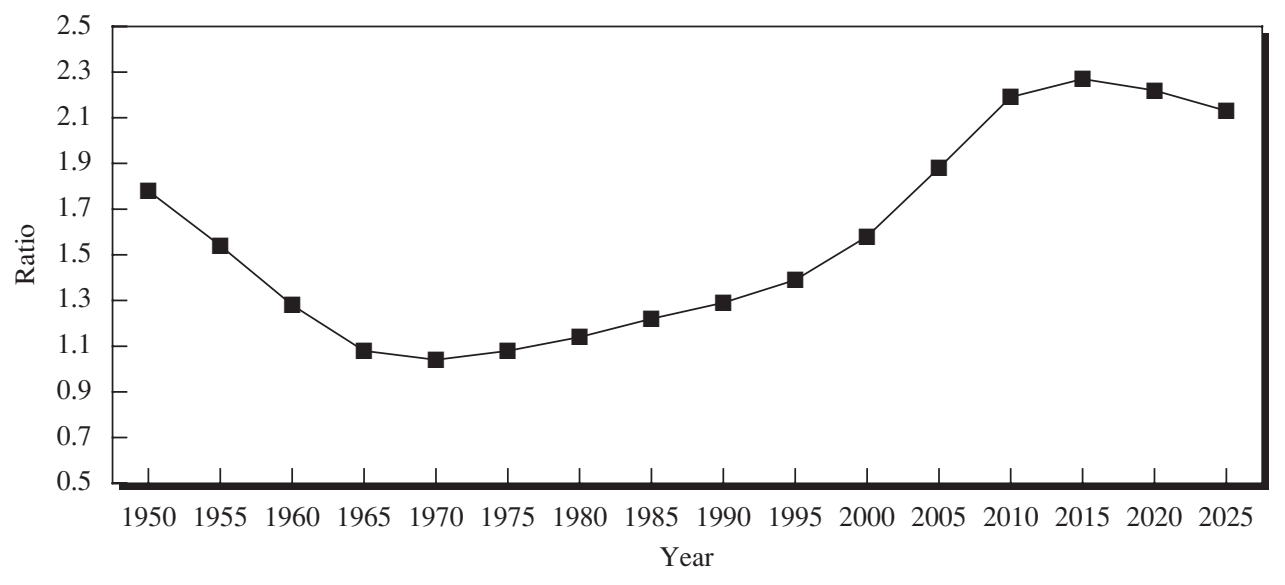

Source: UN 2001.

lation (those aged 15-65) relative to the nonworking population (those younger than 15 and older than 65) will peak in 2015 at close to 2.3, which is comparable to the peak observed in other East Asian countries but higher than in other regions (Bloom and Canning 2001). Whether Vietnam can take advantage of this demographic bonus depends partly on sound economic policies. Not only must this large cohort of young people be provided with job opportunities, they also need to have confidence in the country's financial system.

\section{CONCLUSION}

A recent International Planned Parenthood Federation news release reporting on an advocacy campaign in Vietnam to increase awareness of the reproductive health needs of young people noted that the HIV prevalence rate among 15-24-year-olds "is relatively high with 0.27 percent of young men and 0.09 percent of young girls affected." ${ }^{20}$ To further emphasize that the reproductive behavior of young people is a cause for concern, it stated that the adolescent fertility rate among 15-19-year-olds in Vietnam is 20 per 1,000 compared to 4 per 1,000 in the Netherlands, and that the Vietnamese abortion rate is one of the highest in the region (International Planned Parenthood Federation 2002). 
The numbers cited in the news release correspond to those published by UN agencies. Their interpretation is problematic, however. HIV prevalence is simply not high among young people in Vietnam compared with rates among the young in many other countries. Moreover, the adolescent fertility rate, although not as low as that of Japan or certain Western European countries, is lower than that of virtually all other developing countries for which such data exist, with the exception of China, and lower than that of most Eastern European countries as well as Canada, England, Iceland, New Zealand, and the United States.

Neither the population community nor young people are well served by wellintentioned policymakers and researchers who overstate the reproductive health problems facing adolescents. As the data on work status demonstrate, the more critical issue for young people in Vietnam is the absence of steady employment, particularly for those in urban areas. In the VASC sample, as noted above, more than half of all out-of-school males and unmarried females resident in urban areas with some secondary education are not currently working. The question arises, how are these young people passing their time? What does it mean for society at large that large numbers of 15-22-year-olds are not gainfully occupied?

Effectively integrating large cohorts of out-of-school adolescents into the economy is a difficult task for any country, but particularly for a country such as Vietnam, which is still at an early stage of economic development. Yet the absence of sufficient employment opportunities for young people not only has implications for the economic wellbeing of young people, but may also have consequences for their health. Although the prevalence of HIV among those aged 15-24 is still low, this situation could change. In light of the ready availability of drugs in Vietnam and the difficulty in providing adequate job opportunities, one can easily imagine a scenario where large numbers of young people become substance abusers. In a country where injectable-drug use is the major route of HIV transmission, this possibility is particularly worrisome. Moreover, poverty and a lack of economic opportunities often lead families, sometimes unwittingly, to send their daughters to work in the commercial sex industry (Willis and Levy 2002). Were HIV to reach epidemic proportions in Vietnam, we do not believe the primary cause would be the sexual activity of the unmarried, which remains at low levels, 
but rather an increase in injectable-drug use and in prostitution, likely consequences of limited employment opportunities.

With the program of Doi Moi the Vietnamese government has made enormous strides in shifting from a centrally planned socialist economy to a market economy. In discussing the restoration of "macroeconomic stability" in the late 1980s, two World Bank economists noted that "Vietnam's development over the past decade represents one of the more dramatic turnarounds in economic history" (Dollar and Litvack 1998:1). Nonetheless, the population is still poor. Although coping with large cohorts of young people needing jobs will not prove easy, if the Vietnamese government pursues an effective development policy, the lives and health of young people may be improved and the country as a whole set on the road to prosperity.

Although no one can fault efforts to educate young people about reproductive health or to provide them with the means to prevent sexually transmitted infections, in a world of limited resources it is valid to ask whether focusing on adolescent reproductive health alone is the best way to minimize future HIV rates. The data presented here suggest that currently, the sexual behavior of adolescents is not what places them most at risk. Rather, the problem is their lack of anything productive to do with their time, coupled with the availability of narcotic drugs. Addressing these fundamental economic problems may help to keep HIV confined to a relatively small portion of the adolescent population. Not addressing these problems could lead to a swelling tide of infected youth-a tide large enough to breach whatever reproductive health defenses have been put in place.

\section{NOTES}

1 In Vietnam, the term "social evils" is used to refer to drug use, commercial sex work, and HIV/AIDS as well as premarital sex among adolescents.

2 The special double issue, entitled “An Asian Journey," was published by TIME, Asia.

3 Hirschman (1994) notes that although the Confucian ideal of patrilocal residence is not the norm in Vietnam, ties between nonresident family members are extremely close, with daily contact between parents and children being common. 
4 Using data from the intercensal surveys, they speculate that the perceived rise in condom use (which, incidentally, is not large, increasing from 1 percent in 1988 to 4 percent in 1994) is attributable in part to higher levels of premarital sex (Goodkind and Anh 1997).

5 Note that it is in developed countries that adolescents are disproportionately represented among abortion clients. Typically, adolescents are overrepresented among women presenting with abortion complications in developing countries (Mensch et al. 1998).

6 Three districts were required in order to sample the requisite distribution of wards/ communes in Ho Chi Minh City.

$7 \quad$ Nationwide, there are approximately 615 districts and 10,477 wards/communes with approximately 1,000 households in each ward/commune. The number of districts per province ranges from eight to 20 .

8 Because of the way the published data are presented, Table 3 compares reports of sex among the unmarried rather than premarital sex among the married and unmarried combined as in Table 2. Also, the data are limited to 15-19-year-olds.

9 See AGI 1998: 51, Appendix Table 3. The proportion of women aged 20-24 who reported having had premarital sex prior to age 20 ranges from 5 to 81 percent in 21 sub-Saharan African countries, with only one country showing a proportion lower than 10 percent. In Latin America, the range for 11 countries is from 10 to 40 percent. Because the oldest women in our sample are 22, we computed the percentage of women aged 20-22 who had had premarital sex by age 20, which yielded 3.6 percent.

10 Note, for comparative purposes, that the high estimates for the same age group in the United States are 0.75 for males and 0.30 for females, two to three times the prevalence found in Vietnam.

11 If the last day was unusual in that it was a holiday or other special day, for example the day of a wedding or a funeral, the respondent was asked about the "last ordinary day." 
12 Although the proportions vary by province, Quang Ninh, which has the highest rate by far, is high for both males and females, evidence that these time-use data are probably reliable.

13 Probed knowledge is defined as recognition of a method after it has been described.

14 Little variability is found by age or province in the analysis of concerns about society; therefore only aggregated data are presented here.

15 Married girls are excluded because young women often quit working at marriage; thus their absence from the labor force is more a reflection of social norms than of the state of the economy.

16 Boys and girls younger than 18 are included in the employment tables because the Vietnam Labor Code permits adolescents aged 15-18 to work and guarantees them the same wages that adults make for a particular job (Edmonds and Turk 2002).

17 The text that introduces the idea of work in the survey reads as follows: "Some people take up jobs for which they are either paid in cash or given merchandisefood, for example - in exchange for their labor. Others work for themselves to earn money_by running a shop, for example, or making handicrafts. Still others work on a family farm or family business, even if they are not paid for this work." The question follows: "Have you ever done any of these things, or any other work?" For those answering "No" to the above: "So you have never done any work for which you were paid or given merchandise; you have never worked for yourself to make money; and you have never worked on a family farm or in a family business?" Thus, the definition of work includes anything the respondent considers work, including (potentially) subsistence work.

18 Data from the 1997-98 Vietnam Living Standards Survey (VLSS), a national survey conducted with technical assistance from the World Bank, indicate rates of "doing nothing" that are somewhat lower than those in the VASC, although they are still high. For example, among 15-22-year-olds resident in urban areas 
in the same six provinces, 14 percent of males and 17 percent of unmarried females are categorized as "doing nothing," compared with 18 percent and 19 percent in the VASC survey. Among out-of-school respondents, 28 percent of males and 32 percent of unmarried females in urban areas are not working according to the VLSS, compared with 47 and 42 percent in the VASC. (VLSS computations performed by Sara Peracca and Sajeda Amin, Population Council.)

In a recent article in the New York Review of Books, Helen Epstein (2002) makes a similar argument about Mozambique and South Africa, where prevention efforts focused on "high-risk" groups such as commercial sex workers have failed to stem the rapid spread of AIDS in the population at large. Epstein contends that, in these countries, economic hardship has led to behaviors among ordinary people (such as, for example, nonprostitutes providing sexual favors in return for economic assistance) that have left them vulnerable to HIV transmission. If this is a true assessment of the situation, combating AIDS will require not only standard public health interventions, but also greater economic development, transparency, and opportunity.

20 These rates are lower than those given in Table 4 because, in order to make the strongest case possible for our argument that HIV is not the major problem in the general population of adolescents, we present high estimates.

\section{REFERENCES}

Alan Guttmacher Institute (AGI). 1998. Into a New World: Young Women's Sexual and Reproductive Lives, New York: AGI.

Anh, Nguyễn Quốc, Nguyễn Mỹ Huong, Daniel Weitraub, and Meredith Caplan. 1999. Adolescent Reproductive Health: Survey and Assessment of Knowledge, Attitudes and Practice of Adolescents in Hai Phong City about Related Reproductive Health Issues. Hanoi: Ban diều hành dụ àn.

Behrman, Jere R. and James C. Knowles. 1999. "Household income and child schooling in Vietnam," The World Bank Economic Review 13(2): 211-256. 
Bélanger, Danièle and Khuat Thu Hong. 1998. "Young single women using abortion in Hanoi, Viet Nam,” Asia-Pacific Population Journal 13(2): 3-26.

_ 1999. "Single women's experiences of sexual relationships and abortion in Hanoi, Vietnam," Reproductive Health Matters 7(14): 71-82.

Birdsall, Nancy and Steven W. Sinding. 2001. "How and why population matters: New findings, new issues," in Nancy Birdsall, Allen C. Kelley, and Steven W. Sinding (eds.), Population Matters: Demographic Change, Economic Growth, and Poverty in the Developing World. New York: Oxford University Press. Pp. 3-23.

Bloom, David and David Canning. 2001. "Cumulative causality, economic growth, and the demographic transition," in Nancy Birdsall, Allen C. Kelley, and Steven W. Sinding (eds.), Population Matters: Demographic Change, Economic Growth, and Poverty in the Developing World. New York: Oxford University Press. Pp. 165-197.

Bruce, Judith and Barbara S. Mensch. 1999. "Taking back young lives: Policy issues for adolescent girls in the developing world," Journal of the American Medical Women's Association 54(3): 153-160.

Bryant, John. 1998. "Communism, poverty, and demographic change in North Vietnam," Population and Development Review 24(2): 235-269.

Desai, Jaikishan. 1998. "Poverty and fertility in Vietnam," in David Dollar, Paul Glewwe, and Jennie Litvack (eds.), Household Welfare and Vietnam's Transition. Washington, DC: The World Bank. Pp. 277-318.

Dollar, David and Jennie Litvack. 1998. "Macroeconomic reform and poverty reduction in Vietnam," in David Dollar, Paul Glewwe, and Jennie Litvack (eds.), Household Welfare and Vietnam's Transition. Washington, DC: The World Bank. Pp. 1-26.

Edmonds, Eric and Carrie Turk. 2002. "Child Labor in Transition in Vietnam.” Policy Research Working Paper No. 2774. Washington, DC: The World Bank.

Epstein, Helen. 2002. "The hidden cause of AIDS," The New York Review of Books 49(8): 43-49. 
Glewwe, Paul and Hanan G. Jacoby. 1998. "School enrollment and completion in Vietnam: An investigation of recent trends," in David Dollar, Paul Glewwe, and Jennie Litvack (eds.), Household Welfare and Vietnam's Transition. Washington, DC: The World Bank, Pp. 201-234.

- 2002. "Economic Growth and the Demand for Education: Is There a Wealth Effect?" Stanford University Center for Research on Economic Development and Policy Reform, Working Paper No. 123. Stanford, CA: Stanford University.

Goodkind, Daniel M. 1994. "Abortion in Vietnam: Measurements, puzzles, and concerns," Studies in Family Planning 25(6): 342-352.

—. 1995. "Vietnam's one-or-two-child policy in action," Population and Development Review 21(1): 85-111.

Goodkind, Daniel and Phan Thuc Anh. 1997. "Reasons for rising condom use in Vietnam," International Family Planning Perspectives 23(4): 173-178.

Haughton, Jonathan. 1997. "Falling fertility in Vietnam," Population Studies 51: 203 211.

Henshaw, Stanley K., Susheela Singh, and Taylor Haas. 1999. "The incidence of abortion worldwide," International Family Planning Perspectives 25 (supplement): S30-S38.

Hirschman, Charles. 1994. "Family and household structure in Vietnam." Paper presented at the annual meeting of the Association for Asian Studies, 18-20 March, Boston.

Hong, Khuat Thu. 1998. "Study on Sexuality in Vietnam: The Known and Unknown Issues." Regional Working Papers. Hanoi: Population Council.

Hong, Khuat Thu and Tran Thi Phuong Mai. 1998. "Responding to the reproductive health needs of adolescents and youth in Vietnam." Country paper submitted to technical meeting INT/96/P03 on "Reproductive Health Policy Makers and Researchers on RH Needs of Adolescents and Youth in the Asian sub-Region." Bangkok, 23-27 November. 
International Planned Parenthood Federation. 2002. "Gender equity, HIV/AIDS and football in Vietnam.” <http://ippfnet.ippf.org/pub/IPPF_News/News_Details_s.asp? ID=1730> Accessible 7 February 2002.

Knodel, John, Phan Thuc Anh, Truong Viet Dung, and Dao Xuan Vinh. 1995. "Why is oral contraceptive use in Vietnam so low?" International Family Planning Perspectives 21(1): 11-18.

Knodel, John and Gavin W. Jones. 1996. "Post-Cairo population policy: Does promoting girls' schooling miss the mark?" Population and Development Review 22(4): 683-702.

Long, Lynellyn D., Lyn Nguyen Henderson, Le Thi Phuong Mai, and Carl Haub. 2000. The Doi Moi Generation: Coming of Age in Vietnam Today. Hanoi: Population Council.

McCarthy, Terry. 2000. "The kids are all right,” TIME 156(7/8): 74-77.

Mensch, Barbara, Judith Bruce, and Margaret E. Greene. 1998. The Uncharted Passage: Girls' Adolescence in the Developing World. New York: Population Council.

Merli, M. Giovanna. 1998. "Mortality in Vietnam, 1979-1989," Demography 35(3): 345-360.

Morrison, Donald. 2000. “Marching orders,” TIME 156(7/8): 4.

Nhan, Vu Quy and Ngo Dang Minh Hang. 1996. "Reproductive Behavior of Unmarried Urban Students of Age 17-24 in Vietnam.” Research Report Series. Hanoi: National Committee for Population and Family Planning and Centre for Population Studies and Information.

Population Council and the Institute of Sociology. 2000. Adolescents and Social Change in Vietnam. New York: Population Council.

Schiffrin, Anya. 1999. "Vietnam's youth are losing focus of why the party never ended," Asian Wall Street Journal 16-17 July: 1, 6.

Singh, Susheela, Deirdre Wulf, Renee Samara, and Yvette P. Cuca. 2000. "Gender differences in the timing of first intercourse: Data from 14 countries," International Family Planning Perspectives 26(1): 21-28, 43. 
UNAIDS and WHO. 2000. Report on the Global HIVIAIDS Epidemic. Geneva: UNAIDS.

United Nations. 2001. World Population Prospects: The 2000 Revision, Volumes I and II. New York: United Nations.

United Nations Development Programme (UNDP). 1998. "East Asia: From miracle to crisis." Staff paper. New York: UNDP.

Van Phai, Nguyen, John Knodel, Mai Van Cam, and Hoang Xuyen. 1996. "Fertility and family planning in Vietnam: Evidence from the 1994 Inter-censal Demographic Survey," Studies in Family Planning 27(1): 1-17.

Williamson, Jeffrey G. 2001. "Demographic change, economic growth, and inequality," in Nancy Birdsall, Allen C. Kelley, and Steven W. Sinding (eds.), Population Matters: Demographic Change, Economic Growth, and Poverty in the Developing World. New York: Oxford University Press. Pp. 106-136.

Willis, Brian M. and Barry S. Levy. 2002. "Child prostitution: Global health burden, research needs and interventions," The Lancet 359(9315): 1417-1422.

Wu, Lawrence L., Steven P. Martin, and Daniel A. Long. 2001. "Comparing data quality of fertility and first sexual intercourse histories," The Journal of Human Resources 36(3): 520-555. 


\title{
POLICY RESEARCH DIVISION WORKING PAPERS
}

\author{
Recent Back Issues
}

133 Mary Arends-Kuenning and Sajeda Amin, "The effects of schooling incentive programs on household resource allocation in Bangladesh."

134 John Bongaarts and Charles F. Westoff, "The potential role of contraception in reducing abortion."

135 John B. Casterline and Steven W. Sinding, "Unmet need for family planning in developing countries and implications for population policy."

*136 Carol E. Kaufman, Thea de Wet, and Jonathan Stadler, "Adolescent pregnancy and parenthood in South Africa."

*137 Valerie L. Durrant and Zeba A. Sathar, "Greater investments in children through women's empowerment: A key to demographic change in Pakistan?"

138 Sajeda Amin, Alaka Malwade Basu, and Rob Stephenson, "Spatial variation in contraceptive use in Bangladesh: Looking beyond the borders."
139 Geoffrey McNicoll, "Managing population-environment systems: Problems of institutional design."

140 Barbara S. Mensch, Barbara L. Ibrahim, Susan M. Lee, and Omaima ElGibaly, "Socialization to gender roles and marriage among Egyptian adolescents."

141 John Bongaarts and Elof Johansson, "Future trends in contraception in the developing world: Prevalence and method mix."

*142 Alaka Malwade Basu and Sajeda Amin, "Some preconditions for fertility decline in Bengal: History, language identity, and an openness to innovations."

143 Zeba Sathar, Cynthia B. Lloyd, Cem Mete, and Minhaj ul Haque, "Schooling opportunities for girls as a stimulus for fertility change in rural $\mathrm{Pa}$ kistan."

* No longer available 
144 John Bongaarts, "Household size and composition in the developing world."

145 John B. Casterline, Zeba A. Sathar, and Minhaj ul Haque, "Obstacles to contraceptive use in Pakistan: A study in Punjab."

146 Zachary Zimmer, Albert I. Hermalin, and Hui-Sheng Lin, "Whose education counts? The impact of grown children's education on the physical functioning of their parents in Taiwan."

147 Philomena Nyarko, Brian Pence, and Cornelius Debpuur, "Immunization status and child survival in rural Ghana."

*148 John Bongaarts and Zachary Zimmer, "Living arrangements of older adults in the developing world: An analysis of DHS household surveys."

149 Markos Ezra, "Ecological degradation, rural poverty, and migration in Ethiopia: A contextual analysis."
150 Cynthia B. Lloyd, Sahar El Tawila, Wesley H. Clark, and Barbara S. Mensch, "Determinants of educational attainment among adolescents in Egypt: Does school quality make a difference?"

151 Barbara S. Mensch, Paul C. Hewett, and Annabel Erulkar, "The reporting of sensitive behavior among adolescents: A methodological experiment in Kenya."

152 John Bongaarts, "The end of the fertility transition in the developed world."

153 Mark R. Montgomery, GebreEgziabher Kiros, Dominic Agyeman, John B. Casterline, Peter Aglobitse, and Paul Hewett, "Social networks and contraceptive dynamics in southern Ghana."

*154 Paul C. Hewett and Mark R. Montgomery, "Poverty and public services in developing-country cities."

* No longer available 
155 Zachary Zimmer, Linda G. Martin, and Ming-Cheng Chang, "Changes in functional limitations and survival among the elderly in Taiwan: 1993, 1996, and 1999."

156 John Bongaarts and Griffith Feeney, "How long do we live?"

157 Zachary Zimmer and Sovan Kiry Kim, "Living arrangements and socio-demographic conditions of older adults in Cambodia."

158 Geoffrey McNicoll, "Demographic factors in East Asian regional integration."

159 Carol E. Kaufman, Shelley Clark, Ntsiki Manzini, and Julian May, "How community structures of time and opportunity shape adolescent sexual behavior in South Africa."
160 Julia Dayton and Martha Ainsworth, "The elderly and AIDS: Coping strategies and health consequences in rural Tanzania."

161 John Bongaarts, "The end of the fertility transition in the developing world."

162 Naomi Rutenberg, Carol E. Kaufman, Kate Macintyre, Lisanne Brown, and Ali Karim, "Pregnant or positive: Adolescent childbearing and HIV risk in South Africa."

163 Barbara S. Mensch, Wesley H. Clark, and Dang Nguyen Anh, "Premarital sex in Vietnam: Is the current concern with adolescent reproductive health warranted? 